\title{
Climate change and chill accumulation: implications for tree fruit production in cold winter regions
}

\author{
Hossein Noorazar ${ }^{1}$ - Lee Kalcsits ${ }^{2}$. Vincent \\ P. Jones ${ }^{3}$ - Matthew S. Jones ${ }^{3}$ - Kirti \\ Rajagopalan $^{1}$
}

Received: date / Accepted: date

\begin{abstract}
Winter chill accumulation is critical for the productivity and profitability of perennial tree fruit systems. Several studies have quantified the impacts of global warming on chill accumulation in the warmer tree fruit and nut production regions of the world, where insufficient chill events are currently prevalent and the frequency of these events is increasing. In contrast, we focus on an important tree fruit production region with relatively cold winters and current absence of insufficient chill events, and quantify the potential for introduction of these risks under climate change and understand the key drivers and management implications. Our case study is the Pacific Northwest United States (PNW)- the leading apple producing region in the county. Our results identify large spatial variations in response within the PNW, with chill accumulation projected to increase in northern areas but decrease in southern areas. There is also spatial and temporal variation in the driving factors resulting in changes to chill accumulation. Our results highlight that with warming, colder regions can potentially shift from being regions where the spring phenology is primarily forcing-driven to one where the chilling and forcing processes significantly overlap and the dynamic interplay between these processes become important. These complex dynamics potentially create new production risks which have not historically been a concern and necessitate planning for management strategies such as overhead irrigation for cooling and chemical management of budbreak. Future

\footnotetext{
${ }^{1}$ Department of Biological Systems Engineering, Washington State University, Pullman, WA 99164, USA

${ }^{2}$ Department of Horticulture, Tree Fruit Research and Extension Center, Washington State University, 1100 North Western Avenue, Wenatchee, WA 98801, USA; lee.kalcsits@wsu.edu

${ }^{3}$ Department of Entomology, Tree Fruit Research and Extension Center, Washington State matthew.s.jones@wsu.edu
} University, 1100 North Western Avenue, Wenatchee, WA 98801, USA; vpjones@wsu.edu,

Correspondence: kirtir@wsu.edu
\end{abstract}


work should focus on understanding, modelling and projecting responses across these overlapping chilling and forcing processes. Additionally, given significant spatial differences across a relatively small geographic range, it is also critical to understand and model these dynamics at a local landscape resolution for regions such as the PNW.

Keywords climate change $\cdot$ chill requirement $\cdot$ global warming $\cdot$ Dynamic Model $\cdot$ tree fruit $\cdot$ dormancy $\cdot$ bloom

\section{Contents}

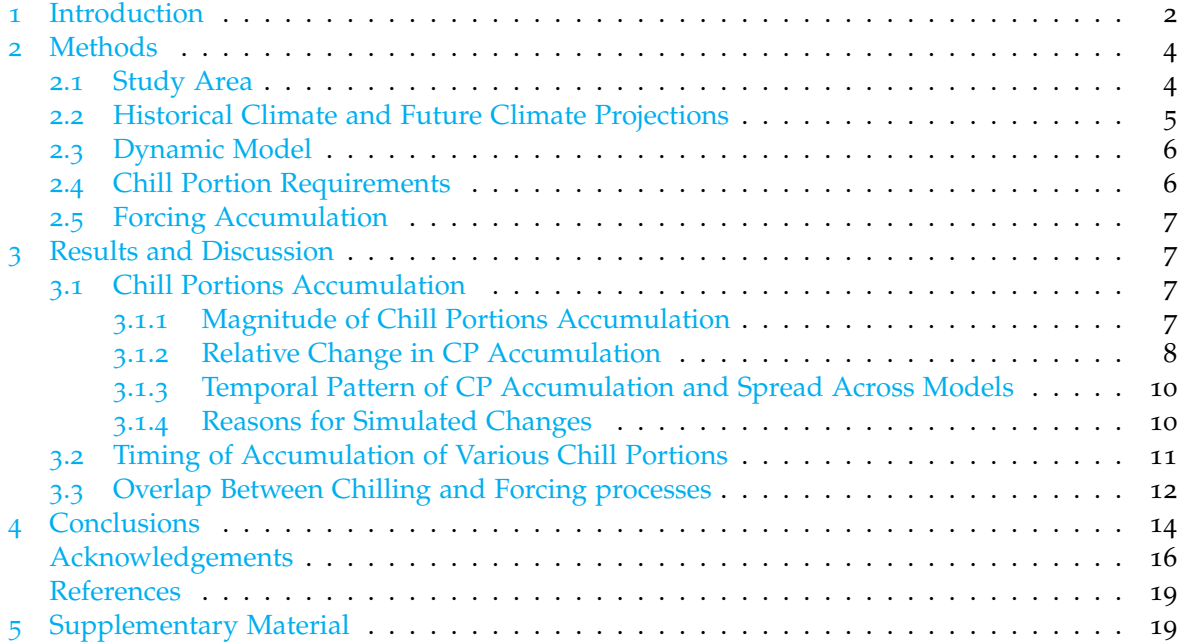

\section{Introduction}

Winter chill accumulation is critical for productive and profitable temperate tree fruit production systems. Specifically, chilling affects the emergence from endodormancy, transition to ecodormancy, and the resumption of growth in spring [1]. Commercial varieties have a breadth of chilling requirements that make them suitable for diverse regions $[2,3,4]$. Insufficient chill accumulation has adverse impacts (e.g. increased flower bud abscission, nonuniform bud break, reduced flower and fruit quality), affecting both fruit and vegetative development [5]. Currently, these issues are important in warmer temperate tree-fruit growing regions such as Israel, South Africa, Spain, and California where varietal selection can be often be based largely on chill requirements $[6,7,8,9,10,11]$. While climate change impact studies on insufficient chill accumulation have focused on these currently at-risk areas $[7,8,9,12,13,14,15,16]$, future warming and associated decreases or delays in winter chill accumulation can introduce risks in regions with historically cooler winters. 
Dormancy in tree fruit species is a time period where buds remain inactive. Establishing more accurate terminology, Lang et al. [17] proposed two dormancy stages - endodormancy and ecodormancy - defined by physiological and environmental inhibitions of regrowth, respectively. The stages are not discrete, but dynamic in response to environmental stimuli [18]. Dormancy induction in fall is regulated by either photoperiod, or temperature, or a combination of both $[19,20,21]$. Once dormancy is induced, a tree will remain endodormant until it fulfills its chilling requirement at which point it enters ecodormancy when environmental conditions prevent budbreak; chilling and heating (forcing) requirements need to be fulfilled for budbreak. The chill and heat accumulation periods can overlap. However, in relatively cool temperate climates, chill requirements are frequently met during early winter and spring phenology is primarily affected by the forcing requirements and minimally affected by chill accumulation [22,23]. In contrast to relatively warmer regions, which currently experience higher risks of insufficient chill accumulation, there can be high overlaps between chilling and forcing processes and the dynamic interplay between them are more relevant for spring phenology and bud break [22]. With climate change, regions with cold winters can face delayed chill accumulation and advanced forcing resulting in a regime shift: spring phenology shifts from one that is primarily forcing driven to one where the interplay between chilling and forcing processes become more important.

Our objective was to focus on a region with cooler winters - that does not currently face risks of insufficient chill accumulation - and understand the potential evolving risks under climate change. We take the US Pacific Northwest (PNW) as a case study. Although temperate tree fruit crops are grown throughout the continental US, the PNW is the largest apple and sweet cherry production region in the country. The PNW accounted for $67 \%$ of the US apple production in 2018 with a value of $\$ 2.1$ billion, and $87 \%$ of the US fresh cherry production valued at \$470 million (USDA NASS 2018 statistics). Cool wet winters and warm dry summers of the PNW are ideal for specialty crop production. Irrigation water availability and proximity to processors and markets provide an additional competitive advantage [24]. Therefore, while risk of insufficient chill accumulation is currently insignificant in the PNW, given its position as the largest production area in the US for multiple tree fruit, it is an ideal case study to understand future production risks under warming. Only two studies have addressed climate change impacts on chill accumulation for tree fruit in the PNW and they were either restricted to two locations with only one time-frame (2020-2049) [24] or in the larger context of tree fruit production worldwide [3], and diverge in results. In the first study [24], high chill-requirement cultivars in one location faced insufficient chill accumulation as early as the 2030s, but was relatively unaffected in another. In contrast, the second study, which highlighted a location in Canada close to the northern part of the PNW, reported an increase in chill accumulation [3]. Neither considered chill accumulation in the context of forcing nor described potential shifts in processes that drive 
spring phenology. Unrelated to tree-fruit, Harrington and Gould [25] noted potential reductions in chill accumulation in boreal tree species in the PNW.

A variety of temperature-based empirical models have been developed to estimate chill accumulation and the transition from endo- to ecodormancy. These include the Chilling Hour Model [26], the Utah Model [27], and the Dynamic Model $[28,29]$. The Dynamic Model takes into account the positive effect of cool temperatures, the negative effect of high temperatures, the positive effect of moderate temperatures, the effect of moderate temperatures alternating with chilling temperatures, and the time heterogeneity of chilling negation. The Dynamic Model has been reported to better capture the dynamic nature of the chilling process compared to other models $[2,30,31,32]$. This model has been reported to closely align with observations for a variety of crops and cultivars $[8,33,34]$, and for a variety of climatic regimes [30, 35]. Moreover, the Dynamic Model has been shown to work well in warmer climatic regimes $[8,28,30]$-critical in the context of climate change and a shift to warmer temperature regimes.

Our study takes a spatially-explicit approach that covers all current tree fruit production areas in the PNW and aims to (a) quantify changes to risk of insufficient chill accumulation as a result of climate change in colder treefruit production regions, and (b) describe factors that lead to this change in risk. We do this by driving the Dynamic Chilling Portions Model $[28,29]$ with historical climate and future climate projections, and accounting for shifts in the timing of conditions conducive to forcing accumulation. The results of this study will improve our understanding of productions risks related to chill accumulation in regions that currently have relatively cooler winters. It can also help PNW growers develop adaptation strategies for potential new insufficient chill accumulation risks they are not currently exposed to, and sustain the region's standing as the major apple and cherry production region in the US.

\section{Methods}

\subsection{Study Area}

Apple and cherry production areas in the PNW are primarily in Washington State with some production in Idaho and Oregon states. We identified tree fruit growing areas by overlaying two 2018 agricultural land use datasets on our gridded climate dataset (described below) and resulted in $\sim 2300$ simulation grids (Fig. I). For the Washington State part of our study area we used the Agricultural Land Use Database created the the Washington State Department of Agriculture [36]. For the remaining areas we used Cropland Data Layer created by the United States Department of Agriculture [37]. To highlight the spread in results, we also picked four representative locations spanning the breadth of our study area (Figure 1). The spread of elevation and climate data across these four locations are provided in Table 1. 


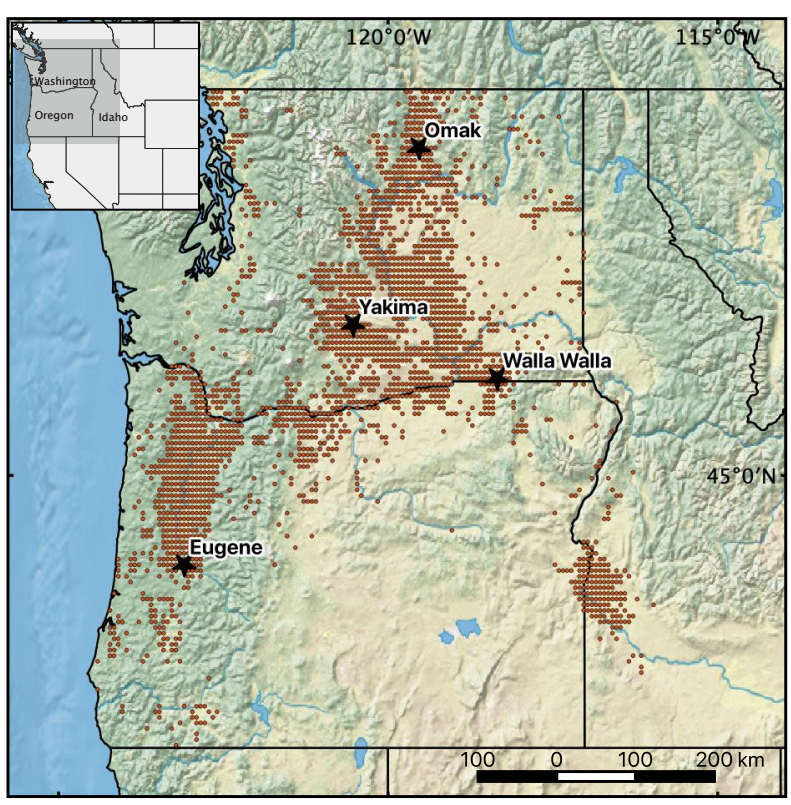

Fig. I Map of the study domain. Red dots correspond to tree fruit growing areas that we simulated. Stars correspond to four locations (Omak, Yakima, Walla Walla, Eugene) across the study domain that we selected to highlight some results in depth.

Table 1 Elevation and climate information for the four representative locations.

\begin{tabular}{|l|l|l|l|l|l|}
\hline Location & Elevation $(\mathrm{m})$ & $\begin{array}{l}\text { Ann. Temp. } \\
\text { Mean }\left({ }^{\circ} \mathrm{C}\right)\end{array}$ & $\begin{array}{l}\text { Winter Temp. } \\
\text { Mean }\left({ }^{\circ} \mathrm{C}\right)\end{array}$ & $\begin{array}{l}\text { Ann. Precip. } \\
\text { Mean }(\mathrm{mm})\end{array}$ & $\begin{array}{l}\text { Winter Precip. } \\
\text { Mean }(\mathrm{mm})\end{array}$ \\
\hline Omak & 318.7 & 9.9 & 4.2 & 312.1 & 203.8 \\
\hline Yakima & 333.2 & 10.6 & 5.6 & 220.1 & 160.7 \\
\hline Walla Walla & 272.9 & 12.2 & 7.4 & 459.7 & 317.7 \\
\hline Eugene & 173.9 & 11.5 & 8.5 & 1164.4 & 934.2 \\
\hline
\end{tabular}

2.2 Historical Climate and Future Climate Projections

Historical simulations (1979-2016) were based on the gridded meteorological observations product -GridMET [38]. Future climate projections (2006-2099) were based on the Coupled Model Intercomparison Project 5 (CMIP5; [39]) which were downscaled and bias corrected to the $4 \mathrm{~km}$ resolution based on the Modified Multivariate Adaptive Constructed Analog (MACA) method [40], and subsequently re-gridded to the $1 / 16$ degree $(\sim 6 \mathrm{~km})$ resolution by linear interpolation for computational efficiency. While the future simulations start from 2006, we use data starting from 2026 for aggregation into three timeframes: 2026-2050, 2051-2075, and 2076-2099. Nineteen climate projections under two representative concentration pathways (RCPs) were used for a total of 38 projections that captured the range in uncertainty in projections. The 19 models used in this study were bcc-csm1-1, bcc-csm1-1-m, BNU-ESM, CanESM2, CCSM4, CNRM-CM5, CSIRO-Mk3-6-o, GFDL-ESM2G, GFDL-ESM2M, 
HadGEM2-CC 365, HadGEM2-ES365, inmcm4, IPSL-CM5A-LR, IPSL-CM5AMR, IPSL-CM5 B-LR, MIROC-ESM-CHEM, MIROC 5 , MRI-CGCM3, and NorESM1M. The RCP 4.5 scenario assumes a stabilization or reduction of greenhouse gas emissions starting around mid-century while the RCP 8.5 is an extreme "no climate policy" scenario that assumes increasing emissions until the end of the century and is associated with relatively high temperature increases post mid-century compared with RCP 4.5 [41]. The temperature data were at a daily timestep and were then disaggregated into an hourly timestep using a sine-logarithmic algorithm [42].

\subsection{Dynamic Model}

The Dynamic Model [28, 29], computes chill accumulation in units referred to as "chill portions" (CP). Chill accumulation is considered a two-step process. The first step is a reversible intermediary process where chill accumulates under low temperatures (a bell curve between $-2^{\circ} \mathrm{C}$ and $13^{\circ} \mathrm{C}$ with optimal accumulation around $6^{\circ} \mathrm{C}$ ), with no accumulation under $-2^{\circ} \mathrm{C}$, and potential for a negative accumulation by exposure to higher temperatures. The negation is a complex process that depends on the level, duration and cycle of exposure to high temperatures and only occurs during the intermediary process. Accumulation during this time can also be enhanced by exposure to moderately high temperatures $\left(13^{\circ} \mathrm{C}-16^{\circ} \mathrm{C}\right)$ alternating with lower temperatures such as in a diurnal cycle. Once the intermediate accumulation threshold is surpassed, in the second step, chill accumulation increases by a unit called a chill portion unit. The accumulated chill portion units are conserved and cannot be reversed, and the intermediate level is set back to zero. Further details can be found in $[28,29]$.

The Dynamic Model implementation we used was provided as part of the chillR package for the $\mathrm{R}$ software $[43]^{1}$. The function used is chillR: :Dynamic_Model(.) and requires an hourly temperature time series as input. The daily maximum and minimum temperature inputs from Section 2.2 were converted to hourly temperatures by the chillR: :stack_hourly_temps (.) function in the chillR package that was based on Linvill's work [42]. We used a simulation timeframe of September 1st to March 31st covering the timeframe for winter and spring phenology in our region. Chill accumulation in our area starts later than September 1st and this start date ensures that the Dynamic Model can capture the commencement of chill portions accumulation.

\subsection{Chill Portion Requirements}

Chill portion requirements are species- and cultivar-specific $[2,3]$. For the analysis to be applicable to a range of different tree fruit species and cultivars, we consider chill portion requirement thresholds from 20 to 75 at

\footnotetext{
${ }^{1}$ Our code is available on Github (https:/ / github.com/HNoorazar/Ag/tree/master/chilling)
} 
Table 2 Chill Portions accumulation requirements for some commonly grown varieties in the PNW $[45,46]$.

\begin{tabular}{llr}
\hline & Cultivar & Min. CP Req. \\
\hline Sweet Cherry & Brooks & 37 \\
& Lapins & 35 \\
& Rainier & 45 \\
& Sam & 70 \\
\hline Apple & Golden Delicious & 50 \\
& Gala & $50-55$ \\
\hline
\end{tabular}

increments of 5 chill portions. This is based on the range of values compiled through literature reviews by [2] and [44]. Specific to varieties grown in the PNW, some of the known minimum chill portions requirements $[45,46]$, are listed in Table 2 and they fall within the 20-75 chill portions range considered in this analysis.

\subsection{Forcing Accumulation}

In order to assess shifts in chill accumulation within the context of forcing accumulation, consistent with the approach taken by chill-overlap models (e.g. [47]) we start accumulating heat units when $75 \%$ of a varieties chill requirements are met. Heat units were calculated using the equations of [48], which fits a sine wave to the daily maximum and minimum temperatures and calculates the area under the curve for heat unit accumulation. Given that we are interested in the timing of when forcing accumulation starts taking off, we use a nominal heat accumulation of 25 heat units as a threshold. We used a base temperature of $6.1^{\circ} \mathrm{C}$, an upper threshold of $25.9^{\circ} \mathrm{C}$, and the vertical cutoff approach to accumulate daily values of heat units.

\section{Results and Discussion}

In this section, regional spatial maps of average results are presented. Four representative locations (Fig. I) are used to highlight temporal aspects and the spread of results from the 19 climate models.

\subsection{Chill Portions Accumulation}

\subsubsection{Magnitude of Chill Portions Accumulation}

Historically, the southwestern tree fruit growing areas of Oregon State (Willamette Valley) accumulated the most, and the northern parts of Washington State accumulated the least chill portions (CP) units (Fig. 2). The apparent contradiction of the warmer areas (Willamette Valley) having the most CP units and the colder areas having the least is a function of colder areas having a 
higher exposure to temperatures lower than $-2^{\circ} \mathrm{C}$-temperatures that result in no $\mathrm{CP}$ accumulation. With climate change, modeled $\mathrm{CP}$ accumulations increased in the relatively colder northern parts of Washington state but decreased in other regions, with larger differences for the RCP 8.5 scenario. By the end of the century, in a switch from historical conditions, the northern parts of Washington state were projected to accumulate more $\mathrm{CP}$ than the southern regions in this study (Fig. 2).

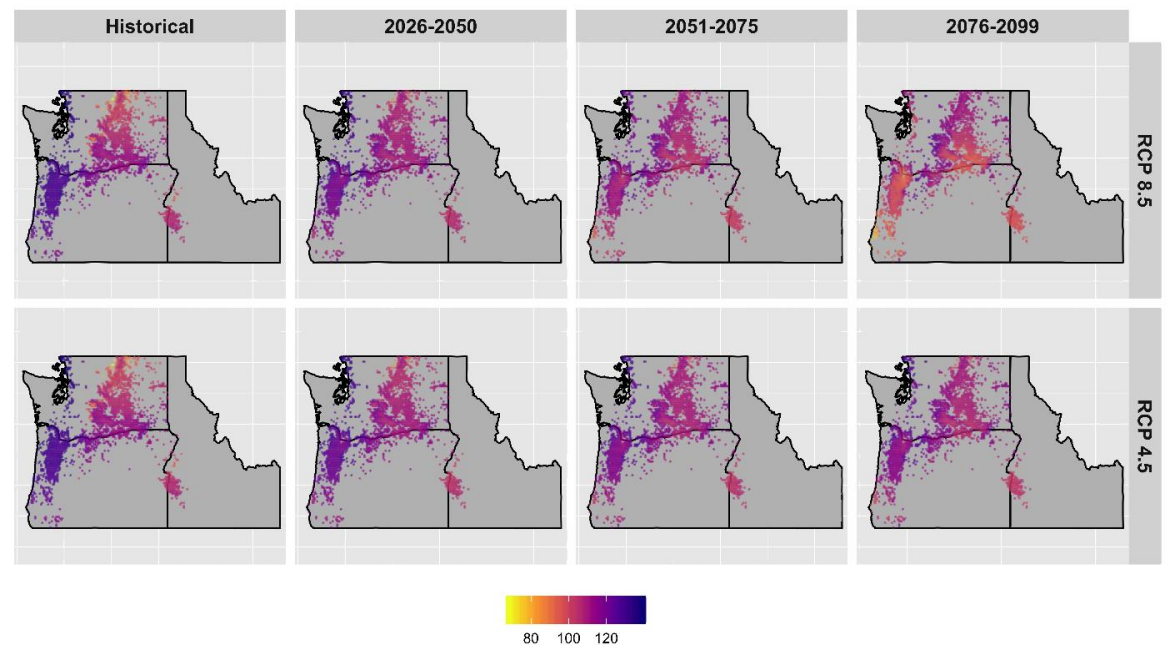

Fig. 2 Average CP accumulation between September 1st and March 31st for different time frames under multiple climate models. First, the accumulated CP by March 31st is computed for each location, year and model. Then for each location, the median of these values is taken over the years within each time window. Finally, the mean of these median values is taken over the 19 climate models. Results are shown for the RCP 8.5 and 4.5 scenarios.

\subsubsection{Relative Change in CP Accumulation}

Our simulations showed both increases and decreases across relatively short geographical ranges (Fig. 3). For the RCP 8.5 scenario, CP accumulation was generally projected to change by $+/-25 \%$ for most areas with some coastal areas showing decreases larger than $40 \%$ (Fig. 3). The negative changes are smaller in magnitude for the RCP 4.5 scenario, especially after 2050, and positive changes are similar to that for RCP 8.5. However, for all regions, by the end of the century, an average of more than $8 \mathrm{o} \mathrm{CP}$ were forecasted to accumulate by March 31st (Fig. 2) for all 19 climate models, even under the RCP 8.5 scenario, implying that even with warming, forecasted temperatures are predicted to be conducive to chill accumulation. These levels of $\mathrm{CP}$ accumulation are above the range of minimum chilling requirements identified for different tree fruit species and cultivars in the PNW (Table 2). This 
suggests that there is limited risk of insufficient chill accumulation even for varieties with high chill requirements. This is in contrast to the results of Huston et al. [24] who quantified the risk for insufficient chill accumulation for two locations in the PNW; Corvallis (close to Eugene) and Wenatchee (close to Yakima). They noted that there is a likely risk of insufficient chill accumulation in Corvallis for high-chill-requirement varieties as early as the 2030s. The differences between our results and those reported by Huston et al. [24] are likely because they used the Chill Hour model while we used the Dynamic Model. The Chill Hour model does not account for dynamic conditions and studies using it tend to show exaggerated responses to warming compared to the Dynamic Model which is better able to capture changes to chilling conditions $[9,30]$. However, the general direction of change in Corvallis/Eugene is consistent across both studies. While Huston et al. [24] does not consider locations in northern Washington state, increases in chill accumulation in these colder regions are consistent with those reported by Luedeling et al. [3] in their global study which highlights changes in the Okanagan Valley in Canada which is just north of the Omak region in northern Washington state.

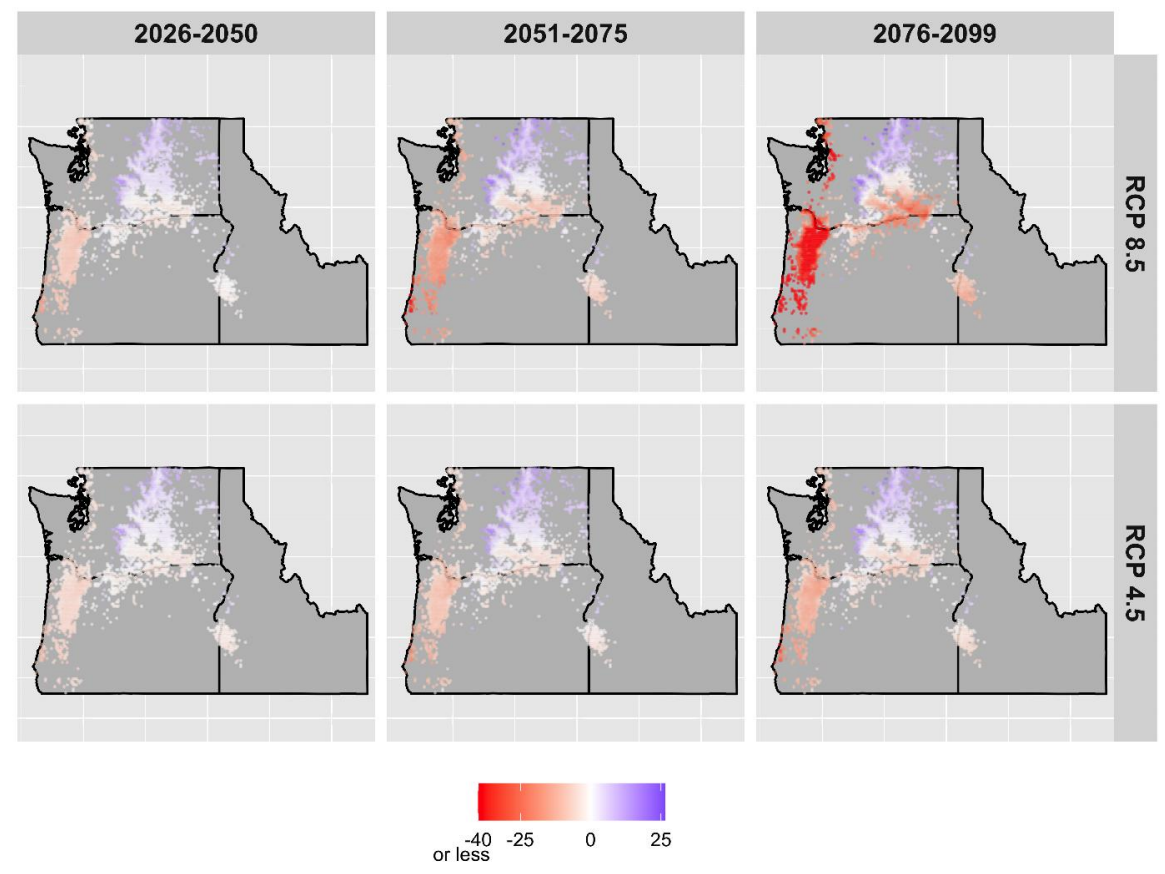

Fig. 3 Percentage differences of CP accumulation between projections and historical observations. In this plot, for a given location and model, we computed the median of CP accumulation across years in three future time periods. Then, the differences between these projections and historical observations were computed. Then, we computed the median of percentage differences over the 19 climatic models. Chill seasons start on September 1st and end on March 31st. Results are shown for the RCP 8.5 and 4.5 scenarios. 


\subsubsection{Temporal Pattern of CP Accumulation and Spread Across Models}

The temporal pattern of changes in CP as well as the spread across the different models for the four representatives locations shows the variable response (Fig. 4) in the rate of change over time and the different RCP scenarios. For RCP 8.5, accumulated CP was projected to increase slightly (from 105.2 in 2025-2026 winter season to 106.6 in 2049-2050) in Omak until about midcentury and then remain relatively flat (Fig. 4) until a small decrease at the of the century (from 106.6 in 2049-2050 to 105.6 in winter season of 20982099). Under RCP 8.5, Yakima stays flat until the mid-century and then it decreases at a nearly linear rate. Accumulated CP for Walla Walla in southern Washington State and Eugene in Oregon was projected to decrease at a nearly linear rate until the end of the century (Fig. 4). This was particularly true for the southwestern location in Eugene, Oregon. While there is a large spread across models, most models indicated meeting minimum $\mathrm{CP}$ requirements in all locations. There are just six climate model-year combinations that indicated a risk of not meeting minimum $\mathrm{CP}$ requirements for species and cultivars with high $\mathrm{CP}$ requirements (above $70 \mathrm{CP}$ ), especially in Oregon State (Eugene) and southeastern Washington State (Walla Walla) towards the end-of-century. The end-of-century minimum and maximum projected CP accumulation for Eugene (RCP 8.5) across the nineteen models were 56.4 and $119.2 \mathrm{CPs}$, respectively. For Omak, the minimum and maximum CP accumulations were 80.7 and $122.5 \mathrm{CP}$, respectively. Under RCP 4.5, changes are minimal as compared to RCP 8.5 as can be seen in Fig. 4.

\subsubsection{Reasons for Simulated Changes}

To highlight the factors producing regional differences presented above, we examined the fraction of total hours (\%) spent in different temperature ranges as relevant for the Dynamic Model (see Section 2.3, and references $[28,29])$ for the simulation timeframe of September 1-March 31 (Table 3). We focused on the RCP 8.5 scenario in this section as this is the scenario with relatively larger projected changes (Fig. 4). The increasing trend in CP accumulation for northern Washington State (Figs. 3 and 4 ) can be attributed to the models projecting significantly less time $(-19 \%)$ with exposure to very cold temperatures (less than $-2^{\circ} \mathrm{C}$ ) which do not accumulate $\mathrm{CP}$, and more time $(7 \%)$ with exposure to a range of temperatures where $\mathrm{CP}$ accumulate. In contrast, other regions see decreases in the relative time of exposure to temperatures conducive to chill accumulation $(-18 \%$ for Eugene). This, coupled with $\mathrm{CP}$ negating effects of temperatures outside the optimum range of $-2^{\circ} \mathrm{C}$ to $13^{\circ} \mathrm{C}$, contributed to more rapid decreases in $\mathrm{CP}$ accumulation for the warmer southern regions. 

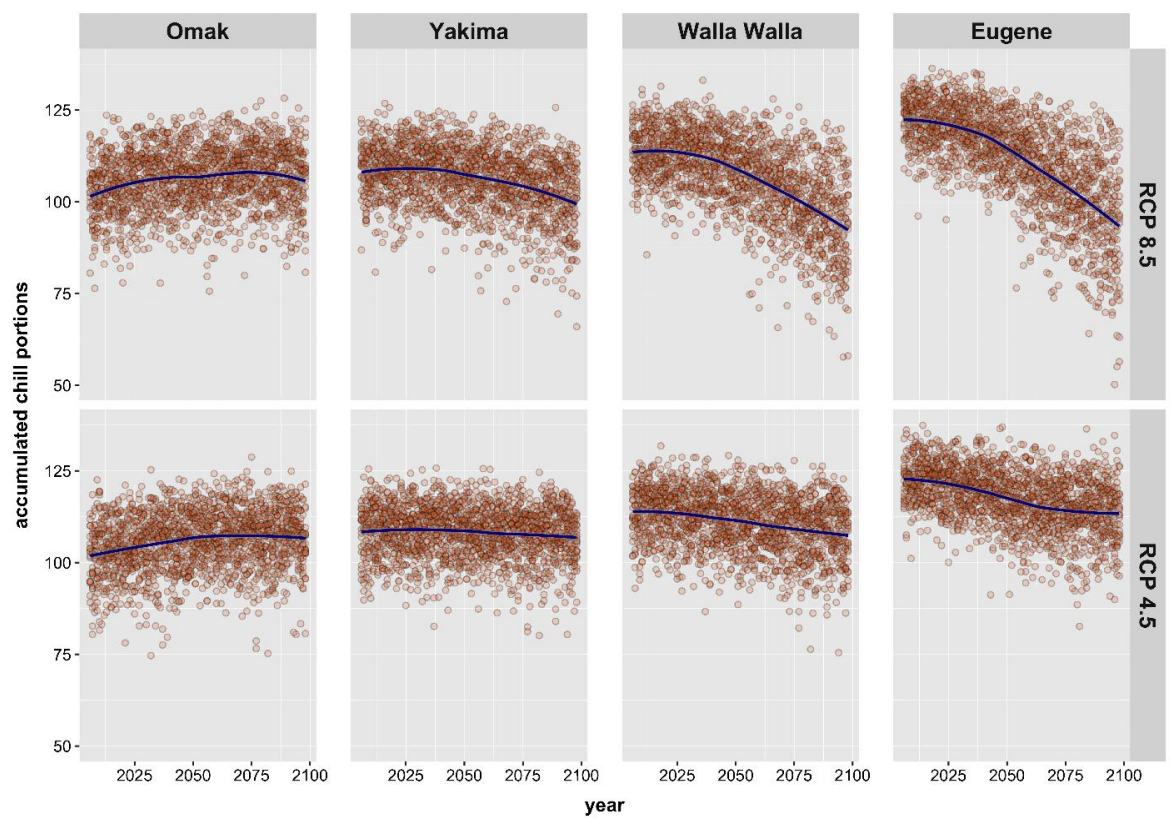

Fig. 4 Temporal pattern of CP accumulation (September 1- March 31st) in Omak, Yakima, Walla Walla, and Eugene for the RCP 4.5 and 8.5 scenarios. The range for a given year corresponds to the 19 climate models.

Table 3 The relative fraction of time (\%) spent within specific temperature intervals between September 1st and March 31st. These intervals correspond to differing effects on $\mathrm{CP}$ accumulation in the Dynamic Model. The results are for the RCP 8.5 scenario.

\begin{tabular}{llllll}
\hline \multirow{3}{*}{ Omak } & & $<-2{ }^{\circ} \mathrm{C}$ & $-2{ }^{\circ} \mathrm{C}-13^{\circ} \mathrm{C}$ & $13{ }^{\circ} \mathrm{C}-16^{\circ} \mathrm{C}$ & $>-16^{\circ} \mathrm{C}$ \\
& Historical & 23.9 & 61.6 & 5.1 & 9.4 \\
& RCP8.5 (2076-2099) & 4.9 & 68.8 & 7.3 & 19 \\
& Difference & -19 & 7.1 & 2.3 & 9.6 \\
\hline \multirow{3}{*}{ Yakima } & Historical & 17.6 & 65.8 & 6 & 10.6 \\
& RCP8.5 (2076-2099) & 4.5 & 65.2 & 9 & 21.2 \\
& Difference & -13.1 & -0.7 & 3.1 & 10.7 \\
\hline \multirow{3}{*}{ Walla Walla } & Historical & 9.4 & 71.3 & 7.1 & 12.3 \\
& RCP8.5 (2076-2099) & 1.7 & 61.3 & 11.8 & 25.3 \\
& Difference & -7.7 & -9.9 & 4.6 & 13 \\
\hline \multirow{3}{*}{ Eugene } & Historical & 2.1 & 79.7 & 7.5 & 10.7 \\
& RCP8.5 (2076-2099) & 0.3 & 62 & 14.4 & 23.3 \\
& Difference & -1.8 & -17.7 & 6.9 & 12.6 \\
\hline
\end{tabular}

\subsection{Timing of Accumulation of Various Chill Portions}

In general, most areas other than the northern region (e.g., Omak) see a projected delay in the timing for meeting $\mathrm{CP}$ thresholds (Fig. 5). For the RCP 8.5 scenario and the end of the century, models consistently projected that, compared with historical timings, the most southern location (Eugene) had a one-month delay in meeting $\mathrm{CP}$ thresholds and a little more than a 2-week 
delay for mid 21st century projections. This delay was consistent with Huston et al. [24]. Although our magnitude of delay is lower than theirs, we are using different models. For the most northern location (Omak), models projected a delay in the timing for chilling fulfillment for the lower CP thresholds and an advancement for reaching greater $\mathrm{CP}$ thresholds with a reversal at thresholds around $45 \mathrm{CP}$ in late December. This implies that increased exposure to temperatures optimal for chill accumulation is primarily in effect only after January for Omak. Even for central Washington State (Yakima), we can see that earlier delays are compensated later in the season with a shrinking delay. This, again, points to the wide variation in the response to warming within this relatively small PNW tree fruit production region.

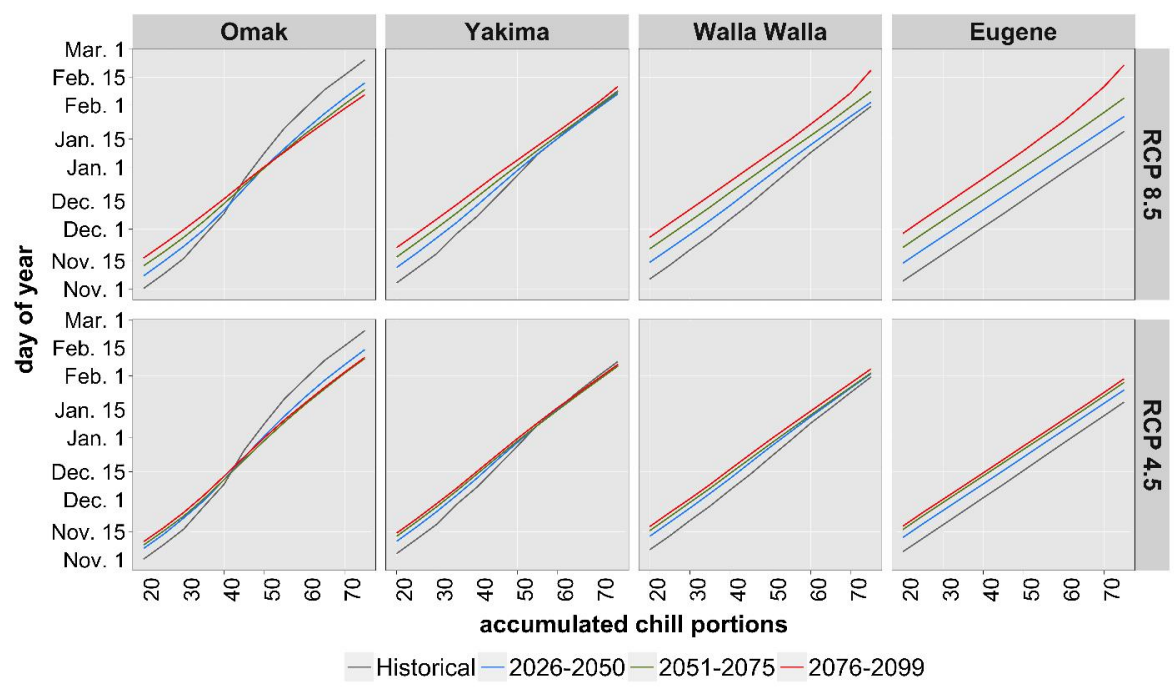

Fig. 5 Day of the Year a given range CP accumulation thresholds (20 to $75 \mathrm{CP}$ ) are met. The range encompasses minimum $\mathrm{CP}$ requirements for the range of tree fruit species and cultivars grown in the region. These are average Day of the Year values across years and averaged across the 19 climate models.

Although the entire range of chill requirements (including the high values in the range) are met by March 31st, delayed fulfillment of chill accumulation thresholds have implications through affecting the overlap between chilling and heating processing and resulting in the dynamics between these processing becoming critical for spring phenology and budbreak [23].

\subsection{Overlap Between Chilling and Forcing processes}

Time series of chilling accumulation and forcing accumulation processes are plotted to get a comparative sense of the timing of chilling process (when 
$75 \%$ and $100 \%$ of chill accumulation are met) and when forcing accumulation starts taking off (using accumulation of 25 heat units as a threshold). Since $\mathrm{CP}$ requirements can widely vary across tree fruit species and cultivars, the figures are plotted for representative medium and high $\mathrm{CP}$ requirement varieties, with $50 \mathrm{CP}$ (e.g. Golden Delicious) and $74 \mathrm{CP}$ (e.g. Cripps Pink) requirements respectively.

Forcing can start accumulating when $75 \%$ of $\mathrm{CP}$ requirements are met, following the typical assumptions in chill-overlap models (e.g. [47]) of spring phenology. Historically, in the PNW, there is a gap between when forcing can start accumulating(when $75 \% \mathrm{CP}$ is met) and when actual forcing accumulation commences after conditions are warm enough (gap between the green and purple horizontal boxes in Figures 6 and 7). With future warming, this gap shrinks as a result of delays in chill accumulation and advances in the timing of when conditions are warm enough to commence forcing accumulation. In fact, in Omak, Yakima, and Walla Walla, historically, in most years, $100 \%$ of CP requirements are met before conditions become conducive for forcing accumulation (black box compared to the purple box). Eugene is a relatively warmer area were some overlap in the timing of chill and forcing accumulation already exists. The slope values noted at the top of each figure are increasing into the future indicating that the rate of early forcing accumulation is increasing.

These results are for the RCP 8.5 scenario. Similar behaviour is exhibited under RCP 4.5 (see Supplementary Materials) although the effects are less pronounced.

Majority of tree fruit production in the PNW is in the region between Omak and Yakima. The gap between the chill accumulation phases and the start of forcing accumulation in Figures 6 and 7 indicate that in these regions, historical spring phenology and bloom are primarily driven by forcing, consistent with the description of colder regions in $[23,50]$. In contrast, with warming we see an increasing overlap between timing of chilling and forcing processes. That is, there is a likely regime shift from being a region where spring phenology is primarily driven by forcing (and there is minimal or non-existent chill accumulation related production risks) to one where spring phenology is dynamically dependent on both chill and heat accumulation processes, with higher risk of issues such as non-uniform bloom and bud abscission that can result in production impacts [5]. This also means simple thermal time models will no longer be able to accurately quantify spring phenology, and chill-overlap models will be necessary. Such models do not currently exist for the PNW and decision support tools for growers [51] utilize thermal time models of forcing which have worked well for historical conditions. Development of chill-overlap models (such as [47]) and using partial least squares regression to identify chill and heat accumulation phases (such as $[50,52]$ ) for the PNW would be critical for future decision support. These areas may also require interventions such as overhead irrigation or chemical induction of budbreak to alleviate new risks. 


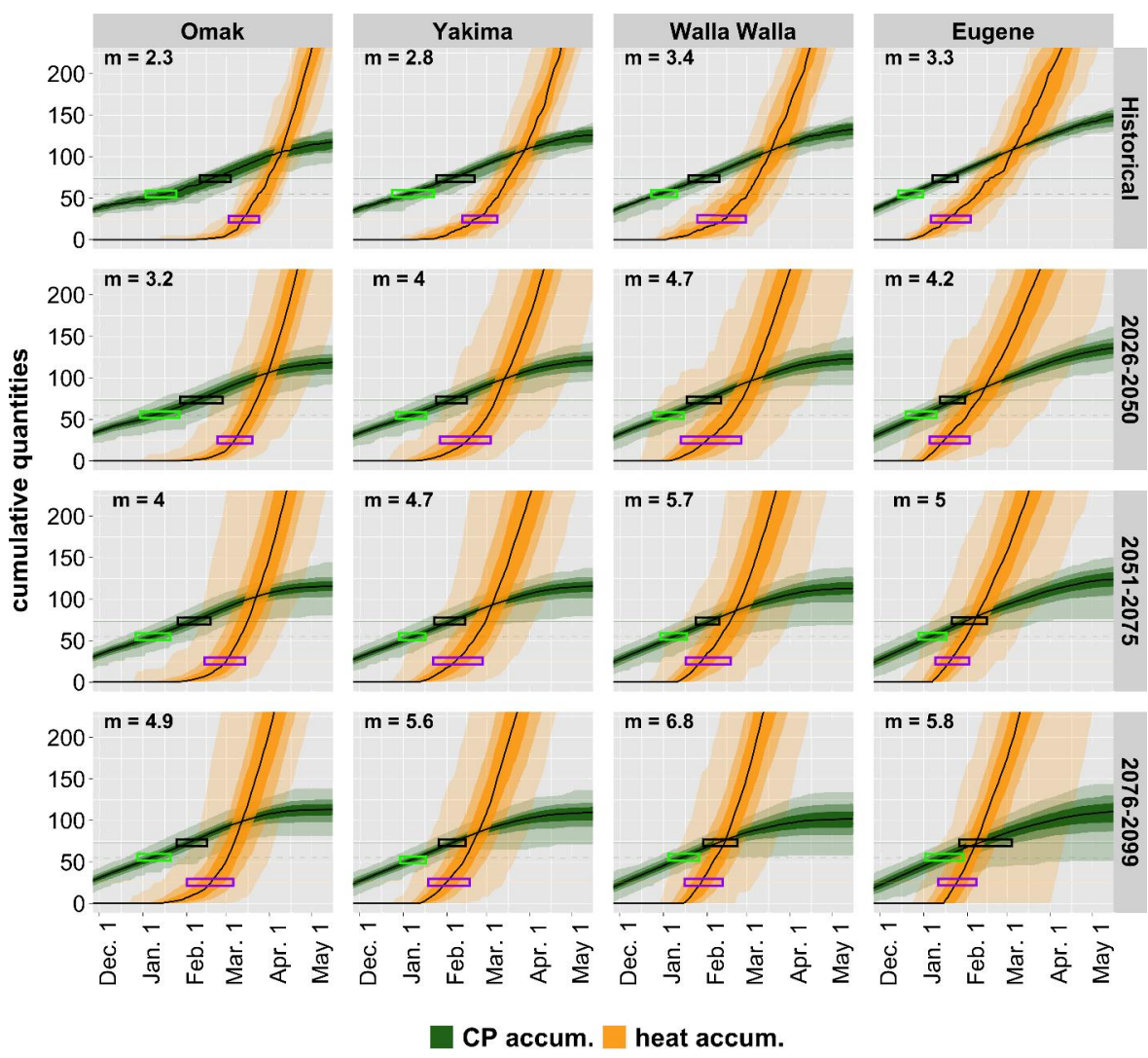

Fig. 6 This plot corresponds to RCP 8.5 for a representative high chill requirement cultivar: Cripps Pink with a minimum chill requirement of $73.3 \mathrm{CP}$ [49]. The green part of the figures are a time series of chill portion accumulation. The range comes from nineteen models and multiple years in the relevant time frame. The shadings correspond to 25th to 75 th percentile (darkest shade), 1oth to goth percentile (lighter shade), and min to max (lightest shade) of CP accumulation. The middle black line is the median. The orange part shows heat accumulation, with similar shading ranges as described for chill accumulation. $m$ noted in each figure is the slope of the median heat accumulation between Feb. 15 and Apr. 15 as an indicator of the rate of forcing accumulation. The heat accumulation process is allowed to begin on the day $55 \mathrm{CP}$ $(75 \%$ of $73.3 \mathrm{CP})$ is accumulated. There are 3 horizontal boxes in these plots that shows the 1oth to goth percentile of the day of year specific events are completed. The bright green box in the green cloud corresponds to the day of the year forcing accumulation is allowed to commence (after $75 \%$ of $\mathrm{CP}$ requirements are met). The purple box in the orange cloud corresponds to the day of the year when heat accumulation starts to take off: $y=25$. The black box corresponds to the day of the year when full $\mathrm{CP}$ requirements are met; in this case $73.3 \mathrm{CP}$.

\section{Conclusions}

The tree fruit producing areas of the Pacific Northwest US experience large spatial variations in the response of chill accumulation to climate change. Moving north, there is a general trend from decreasing chill accumulation to minimal change then to increasing chill accumulation in response to cli- 


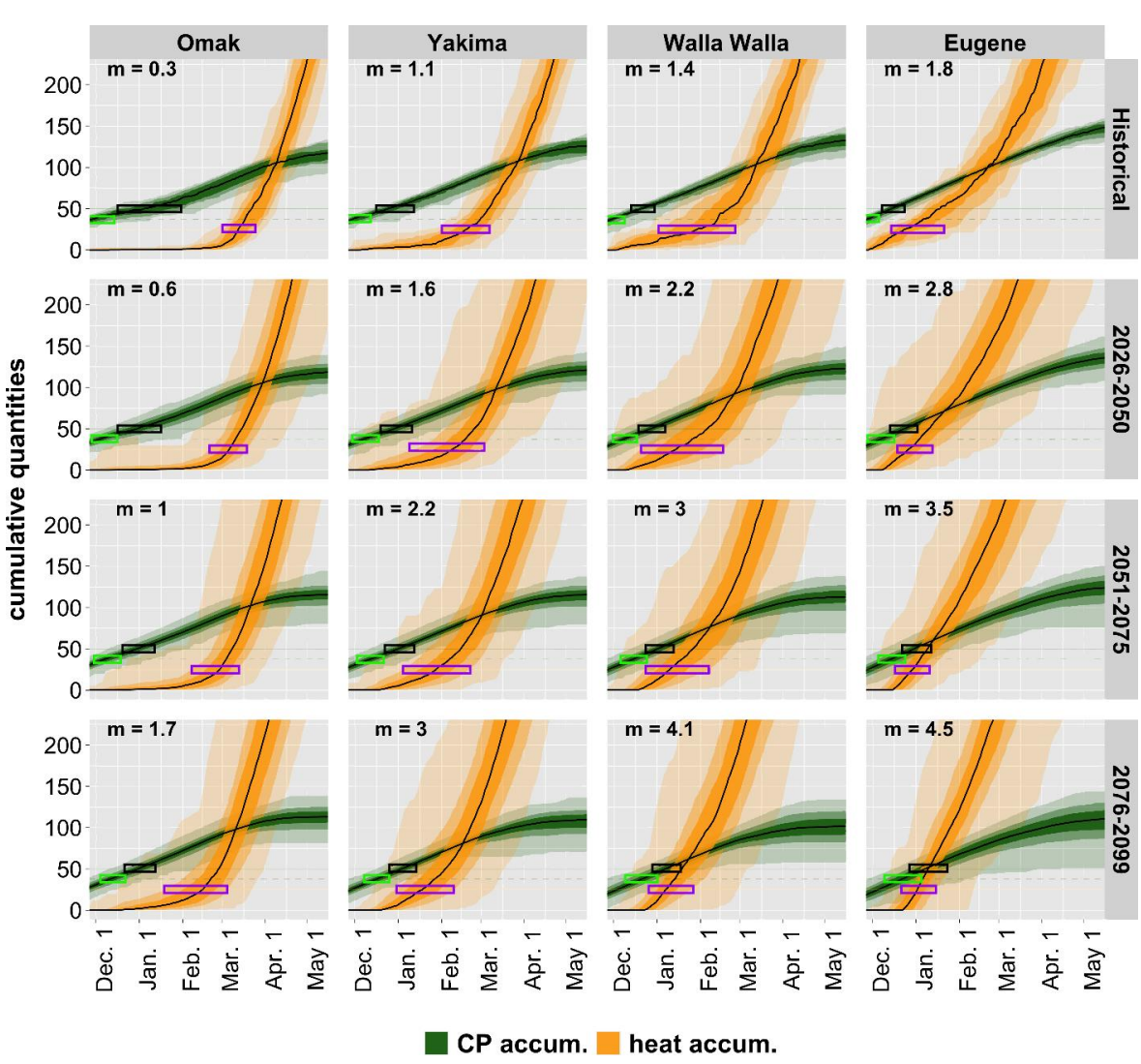

Fig. 7 This is similar to Fig. 6 except for a medium chill requirement variety (e.g. Golden Delicious with a requirement of $50 \mathrm{CP}$ ).

mate change. The key factors contributing to differential responses within the PNW can also vary by region, with more exposure to optimal temperatures likely contributing to changes in the northern areas and chill negation due to higher temperatures contributing to projected changes in other areas.

Even with warming, temperatures continue to be generally conducive to chill accumulation. However, a combination of delayed and reduced chill accumulation along with likely advancement in forcing, will likely lead to many parts of the PNW transitioning from regimes where forcing is the primary driver for spring phenology to one where the dynamics and interplay between chilling and forcing processes becomes dominant for spring phenology. This is true for RCPs 4.5 and 8.5 and varieties with medium and high CP requirements, though more pronounced and occurring earlier for high chill requirement varieties under RCP 8.5. Even though northern Washington State has less risk of insufficient accumulation, other warmer regions of the PNW with potential future risk of insufficient chill accumulation for some cultivars will likely continue as key production regions given 
their competitive advantage in terms of faster time to market. These regions would need to plan for management strategies such as overhead irrigation for cooling, and chemical management of budbreak (with increased production costs) to address potential risks. Adaptation strategies such as overhead irrigation face other obstacles such as availability of irrigation water. Irrigation water rights typically come with a specified season of use, and if future early season evaporative cooling is outside the current permitted season of use, it would require an approval subject to examination that such a change does not adversely affect another water right holder with a higher priority to the use of water.

Significant gaps in our biological understanding of the winter dynamics and dormancy processes in tree fruit create uncertainty in quantifying the response under climate change $[3,53,54]$. Given the potential for introduction of production risks even in colder regions such as the PNW - one of the prominent tree fruit production regions of the US - efforts by the scientific community to address these knowledge gaps will be critical for identifying appropriate adaptation or mitigation strategies. Future modeling efforts must also account for the overlap between fulfillment of chilling requirements (breaking of endodormancy) and environmental conditions promoting budbreak (break of ecodormancy), and the dynamics and tradeoffs across these processes. It is under these conditions where risk to perennial tree fruit production exists and needs to be better understood, modeled, and projected. Given the significant spatial differences across a relatively small geographic range, it is also critical to understand, model and project these dynamics at a local landscape resolution.

Author Contributions Conceptualization, H.N., K.R, L.K, M.J., and V.J.; methodology, H.N., L.K, K.R., V.J.; software, H.N; formal analysis, H.N.; resources, K.R.; data curation, H.N.; visualization, H.N.; supervision, K.R.; project administration, K.R.; funding acquisition, K.R., V.J., L.K.; writing—original draft preparation, K.R. and H.N.; writing—review and editing, V.J., L.K., M.J.

All authors have read and agreed to the published version of the manuscript.

Funding This research was funded by USDA NIFA Western ERME under Award Number 2018-70027-28587.

Conflict of Interest The authors declare no conflict of interest.

Acknowledgements We thank Matthew Brousil (Center for Environmental Research, Education, and Outreach, Washington State University) for preliminary data processing.

Data Availibility The datasets generated during and/or analysed during the current study are available from the corresponding author on reasonable request.

\section{References}

1. M. C. Saure. Dormancy Release in Deciduous Fruit Trees, chapter 6, pages 239-300. John Wiley \& Sons, Ltd, 1985 . 
2. Rebecca Darbyshire, Penelope Measham, and Ian Goodwin. A crop and cultivar-specific approach to assess future winter chill risk for fruit and nut trees. Climatic Change, 137(3):541556,2016

3. Eike Luedeling, Evan H Girvetz, Mikhail A Semenov, and Patrick H Brown. Climate change affects winter chill for temperate fruit and nut trees. PloS one, 6(5):e20155, 2011.

4. RM Samish and S Lavee. The chilling requirement of fruit trees. Publication of the Natl. Univ. Inst. Agr, 511:372-388, 1962.

5. Peter M. Atkinson, C. Jeganathan, Jadu Dash, and Clement Atzberger. Inter-comparison of four models for smoothing satellite sensor time-series data to estimate vegetation phenology. Remote Sensing of Environment, 123:400-417, 2012.

6. Nuria Alburquerque, Federico García-Montiel, Antonio Carrillo, and Lorenzo Burgos. Chilling and heat requirements of sweet cherry cultivars and the relationship between altitude and the probability of satisfying the chill requirements. Environmental and Experimental Botany, 64(2):162-170, 2008.

7. Dennis Baldocchi and Simon Wong. Accumulated winter chill is decreasing in the fruit growing regions of california. Climatic Change, 87(1):153-166, 2008

8. Eike Luedeling, Minghua Zhang, and Evan H Girvetz. Climatic changes lead to declining winter chill for fruit and nut trees in california during 1950-2099. PloS one, 4(7):e6166, 2009.

9. Eike Luedeling, Minghua Zhang, Volker Luedeling, and Evan H. Girvetz. Sensitivity of winter chill models for fruit and nut trees to climatic changes expected in california's central valley. Agriculture, Ecosystems \& Environment, 133(1):23-31, 2009.

10. Eike Luedeling, Minghua Zhang, Gale McGranahan, and Charles Leslie. Validation of winter chill models using historic records of walnut phenology. Agricultural and Forest Meteorology, 149(11):1854-1864, 2009. Special Section on Water and Carbon Dynamics in Selected Ecosystems in China.

11. David Ruiz, Jose Antonio Campoy, and José Egea. Chilling and heat requirements of apricot cultivars for flowering. Environmental and Experimental Botany, 61(3):254-263, 2007.

12. A. A. Farag, A. A. Khalil, M. K. Hassanein, et al. Chilling requirement for deciduous fruits under climate change in egypt. Research Journal of Agriculture and Biological Sciences, 6(6):815-822, 2010

13. SJE Midgley and E Lötze. Climate change in the western cape of south africa: Trends, projections and implications for chill unit accumulation. In IX International Symposium on Integrating Canopy, Rootstock and Environmental Physiology in Orchard Systems 903, pages 1127-1134, 2008.

14. MS Wrege, PH Caramori, FG Herter, S Steinmetz, C Reisser Júnior, R Matzenauer, and HJ Braga. Impact of global warming on the accumulated chilling hours in the southern region of brazil. Acta horticulturae, 872:31-40, 2010.

15. Lauren E Parker and John T Abatzoglou. Warming winters reduce chill accumulation for peach production in the southeastern united states. Climate, $7(8): 94,2019$.

16. H Kaufmann and MM Blanke. Chilling in cherry-principles and projection-a brief introduction. COST Cherry FA1104 Working Group 2 Cherry Phenology, Modelling and Climate Change 1162, pages 39-44, 2014.

17. GA Lang, J_D Early, GC Martin, and RL Darnell. Endo-, para-, and ecodormancy: physiological terminology and classification for dormancy research. HortScience, 22(3):371-377, 1987.

18. LH Fuchigami, CJ Weiser, K Kobayashi, R Timmis, and LV Gusta. A degree growth stage (GS) model and cold acclimation in temperate woody plants, volume 2. Academic Press New York, 1982.

19. Ola M. Heide. Interaction of photoperiod and temperature in the control of growth and dormancy of prunus species. Scientia Horticulturae, 115(3):309-314, 2008.

20. Lee Anthony Kalcsits, Salim Silim, and Karen Tanino. Warm temperature accelerates short photoperiod-induced growth cessation and dormancy induction in hybrid poplar (populus $\times$ spp.). Trees, 23(5):971-979, 2009.

21. Karen K Tanino, Lee Kalcsits, Salim Silim, Edward Kendall, and Gordon R Gray. Temperature-driven plasticity in growth cessation and dormancy development in deciduous woody plants: a working hypothesis suggesting how molecular and cellular function is affected by temperature during dormancy induction. Plant molecular biology, 73(1):49-65, 2010. 
22. Liang Guo, Junhu Dai, Sailesh Ranjitkar, et al. Chilling and heat requirements for flowering in temperate fruit trees. International journal of biometeorology, 58(6):1195-1206, 2014.

23. Yue Yang, Zhengfang Wu, Liang Guo, et al. Effects of winter chilling vs. spring forcing on the spring phenology of trees in a cold region and a warmer reference region. Science of The Total Environment, 725:138323, 2020.

24. Laurie Houston, Susan Capalbo, Clark Seavert, et al. Specialty fruit production in the pacific northwest: adaptation strategies for a changing climate. Climatic Change, 146(1):159171, 2018.

25. Constance A. Harrington and Peter J. Gould. Tradeoffs between chilling and forcing in satisfying dormancy requirements for pacific northwest tree species. Frontiers in Plant Science, 6:120, 2015 .

26. J Bennett et al. Temperature and bud rest period: Effect of temperature and exposure on the rest period of deciduous plant leaf buds investigated. California Agriculture, 4(1):11-16, 1950.

27. Eric A RICHARDSON, RICHARDSON EA, SEELEY SD, and WALKER DR. A model for estimating the completion of rest for "redhaven" and "elberta" peach trees. HORTSCIENCE, 1974 .

28. A Erez and S Fishman. The dynamic model for chilling evaluation in peach buds. In $I V$ International Peach Symposium 465, pages 507-510, 1997.

29. Amnon Erez, Svetlana Fishman, GC Linsley-Noakes, and Peter Allan. The dynamic model for rest completion in peach buds. In II International Symposium on Computer Modelling in Fruit Research and Orchard Management 276, pages 165-174, 1989.

30. Eike Luedeling. Climate change impacts on winter chill for temperate fruit and nut production: A review. Scientia Horticulturae, 144:218-229, 2012.

31. Eike Luedeling and Patrick H Brown. A global analysis of the comparability of winter chill models for fruit and nut trees. International Journal of Biometeorology, 55(3):411-421, 2011.

32. G.C. Linsley-Noakes and P. Allan. Comparison of two models for the prediction of rest completion in peaches. Scientia Horticulturae, 59(2):107-113, 1994.

33. Carlos Miranda, Luis G. Santesteban, and José B. Royo. Evaluation and fitting of models for determining peach phenological stages at a regional scale. Agricultural and Forest Meteorology, 178-179:129-139, 2013. Special Issue:Drought Inner Asia.

34. Jianlu Zhang and Cathy Taylor. The dynamic model provides the best description of the chill process on 'sirora' pistachio trees in australia. HortScience, 46(3):420-425, 2011.

35. Francisco J Pérez, NJ Ormeno, Bryan Reynaert, and Sebastián Rubio. Use of the dynamic model for the assessment of winter chilling in a temperate and a subtropical climatic zone of chile. Chilean journal of agricultural research, 68(2):198-206, 2008.

36. Washington State Department of Agriculture's agricultural land use map. https: //agr.wa.gov/departments/land-and-water/natural-resources/agriculturalland-use, 2018. [Online; accessed 17-Aug.-2021].

37. USDA National Agricultural Statistics Service Cropland data Layer. https:// nassgeodata.gmu.edu/CropScape/, 2018. [Online; accessed 17-Aug.-2021].

38. John T. Abatzoglou. Development of gridded surface meteorological data for ecological applications and modelling. International Journal of Climatology, 33(1):121-131, 2013.

39. Karl E Taylor, Ronald J Stouffer, and Gerald A Meehl. An overview of CMIP 5 and the experiment design. Bulletin of the American meteorological Society, 93(4):485-498, 2012.

40. John T. Abatzoglou and Timothy J. Brown. A comparison of statistical downscaling methods suited for wildfire applications. International Journal of Climatology, 32(5):772-780, 2012.

41. Detlef P Van Vuuren, Jae Edmonds, Mikiko Kainuma, et al. The representative concentration pathways: an overview. Climatic change, 109(1):5-31, 2011.

42. Dale E Linvill. Calculating chilling hours and chill units from daily maximum and minimum temperature observations. HortScience, 25(1):14-16, 1990.

43. Eike Luedeling. chillR: Statistical methods for phenology analysis in temperate fruit trees. $R$ package version $0.54,2013$

44. Chilling accumulation models: Their calculation, explanation, \& comparison. http: //fruitsandnuts.ucdavis.edu/Weather_Services/chilling_accumulation_models/ CropChillReq/. [Online; accessed 17-Aug.-2021].

45. Amnon Erez. Bud dormancy; phenomenon, problems and solutions in the tropics and subtropics. In Temperate fruit crops in warm climates, pages 17-48. Springer, 2000. 
46. Isabel Díez-Palet, Inmaculada Funes, Robert Savé, et al. Blooming under mediterranean climate: Estimating cultivar-specific chill and heat requirements of almond and apple trees using a statistical approach. Agronomy, 9(11):760, 2019.

47. K.S. Pope, D. Da Silva, P.H. Brown, and T.M. DeJong. A biologically based approach to modeling spring phenology in temperate deciduous trees. Agricultural and Forest Meteorology, 198-199:15-23, 2014.

48. G. L. Baskerville and P. Emin. Rapid estimation of heat accumulation from maximum and minimum temperatures. Ecology, 50(3):514-517, 1969.

49. Heidi Parkes, Rebecca Darbyshire, and Neil White. Chilling requirements of apple cultivars grown in mild australian winter conditions. Scientia Horticulturae, 260:108858, 2020.

50. Liang Guo, Junhu Dai, Mingcheng Wang, Jianchu Xu, and Eike Luedeling. Responses of spring phenology in temperate zone trees to climate warming: A case study of apricot flowering in china. Agricultural and Forest Meteorology, 201:1-7, 2015.

51. V. P. Jones, S. Borghi, M. S. Jones, and U. Chambers. WSU-Tree Fruit Decision Aid System. Washington State University. https://decisionaid.systems/. [Online; accessed 17-Aug.2021].

52. Johann Martínez-Lüscher, Paul Hadley, Matthew Ordidge, et al. Delayed chilling appears to counteract flowering advances of apricot in southern uk. Agricultural and Forest Meteorology, 237-238:209-218, 2017

53. Rebecca Darbyshire, Leanne Webb, Ian Goodwin, et al. Challenges in predicting climate change impacts on pome fruit phenology. International journal of biometeorology, 58(6):11191133, 2014 .

54. Andrew D. Richardson, Trevor F. Keenan, Mirco Migliavacca, Youngryel Ryu, Oliver Sonnentag, and Michael Toomey. Climate change, phenology, and phenological control of vegetation feedbacks to the climate system. Agricultural and Forest Meteorology, 169:156-173, 2013.

\section{Supplementary Material}




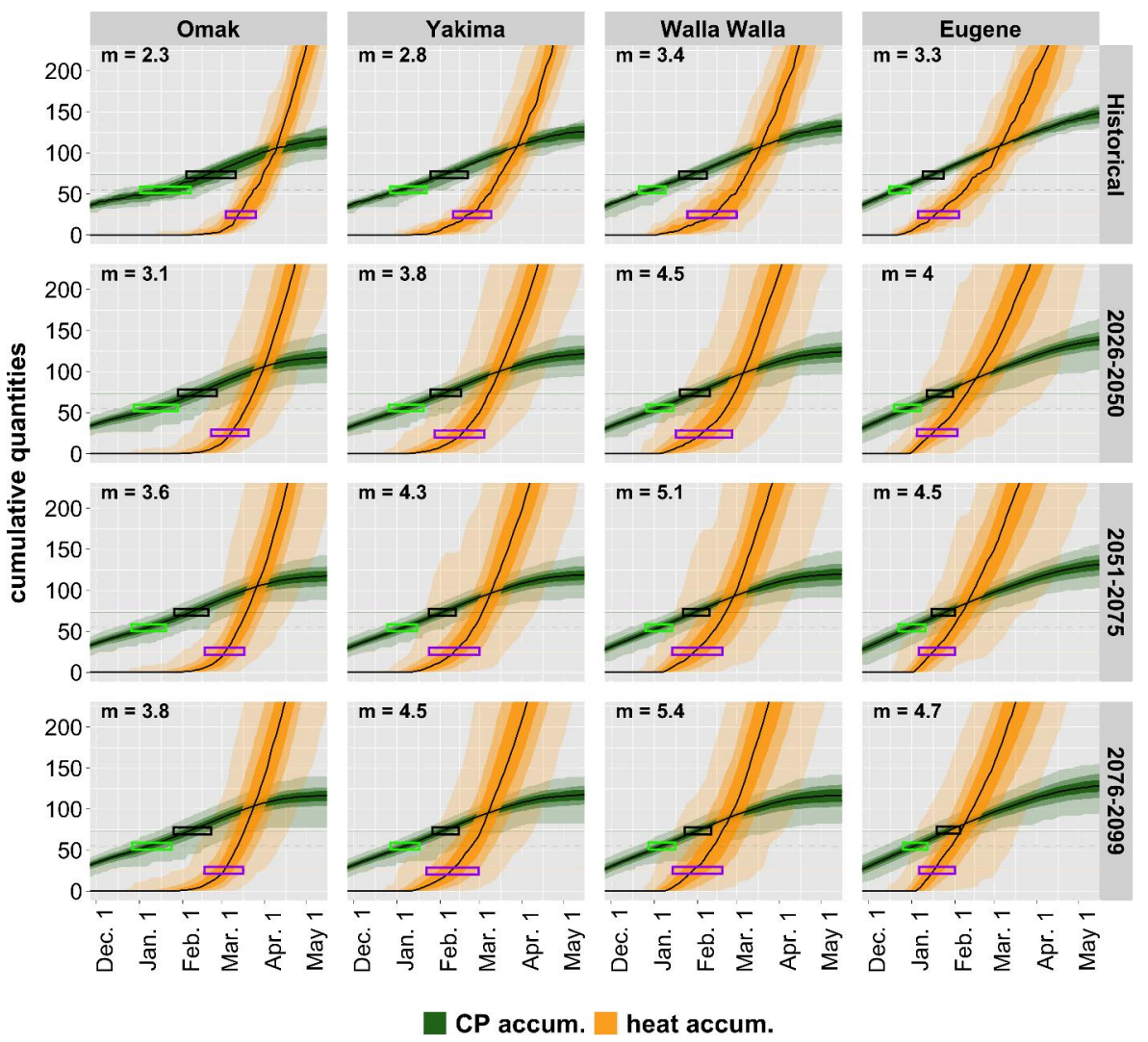

Fig. 8 This is the RCP 4.5 version of Fig. 6 for high chill requirement varieties (e.g. Cripps Pink). 


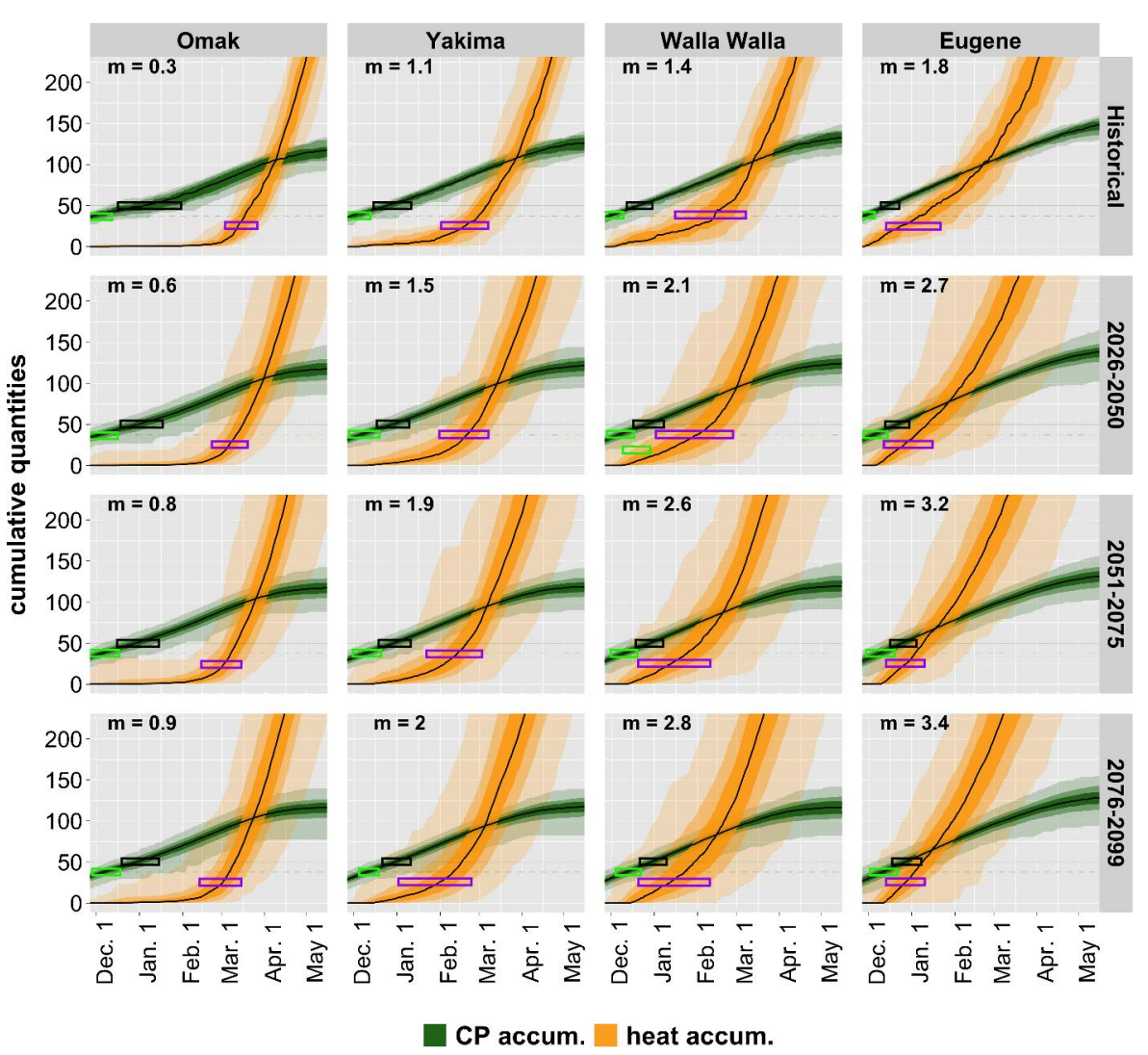

Fig. 9 This is the RCP 4.5 version of Fig. 7 for medium chill requirement varieties (e.g. Golden Delicious). 